\title{
Políticas Docentes no Brasil: Um Estado da Arte
}

BERNARDETE ANGELINA GATTI, ELBA SIQUEIRA DE SÁ BARRETTO,

MARLI ELIZA DALMAZO DE AFONSO ANDRÉ

BRASÍLIA: UNESCO, 2011, 300 p.

Cada vez mais as agendas atualizadas de políticas educativas incluem a figura do professor e outros temas vinculados ao trabalho docente. No projeto do novo Plano Nacional de Educação do Brasil - PNE (2011-2020), a melhoria da qualidade do ensino e a valorização dos profissionais da educação se apresentam como importantes desafios da agenda educacional brasileira. É nessa direção que o livro comentado busca mapear e analisar as políticas docentes produzidas nos diferentes âmbitos - da União, dos estados e dos municípios - e focaliza a formação inicial e continuada para o magistério, a carreira docente e avaliação dos professores; as formas de recepção e acompanhamento dos professores iniciantes bem como os subsídios oferecidos ao seu trabalho. O exame das políticas no âmbito em que são formuladas permitiu às autoras identificar muitos dos seus pressupostos, direcionamentos e diversidade, além das alternativas que sinalizam positivamente a equalização das oportunidades formativas, de carreira e de condições de trabalho, e seus efeitos na qualidade da educação oferecida pelas escolas públicas aos jovens e às crianças.

O livro é resultado de pesquisa abrangente e original e foi desenvolvido em parceria com a Unesco e o Ministério da Educação, com o apoio do Conselho Nacional dos Secretários da Educação - Consed - e da União Nacional dos Dirigentes Municipais - Undime.

As fontes de coleta para o estado da arte das políticas voltadas aos docentes incluíram informações e documentos provenientes dos órgãos gestores das políticas educacionais na esfera federal, nos estados e municípios, além de informações das instituições de ensino superior - IES - e outras entidades ou órgãos de pesquisa. Embora os dados documentais não tenham contemplado a totalidade das redes de ensino no país, as autoras tiveram o cuidado de coletá-los nas Secretarias de Educação de estados brasileiros, do Distrito Federal e de municípios distribuídos pelas cinco regiões do país. Também foram tomados, como fontes de referência, diversos estudos e pesquisas nacionais e internacionais sobre os temas em questão. Ainda com a intenção de aprofundar as análises das políticas docentes e compreender como têm sido implantadas pelos órgãos executores, foram realizados 15 estudos de caso, sendo 5 em Secretarias Estaduais de Educação e 10 em Secretarias Municipais.

Os dados coletados nos estudos de campo com os gestores ou seus representantes buscaram esclarecer aspectos relativos às ações da formação continuada de docentes em exercício na educação básica, bem como aos apoios para seu trabalho e para as iniciativas de valorização do trabalho do professor. A representatividade regional e a relevância, inovação ou abrangência de propostas sobre esses aspectos foram critérios definidores da escolha 
dos estados e municípios em que foram realizados esses estudos. Além disso, foram incluídas Secretarias de Educação com propostas curriculares apoiadas em sistemas apostilados de ensino com a intenção de verificar sua relação com o trabalho docente.

Importante destacar o cuidado das autoras em relação à coleta de dados do estudo e ao seu preciso relato. As redes municipais consideradas foram as que reúnem 150 mil habitantes ou mais, e que se circunscrevem ao universo de municípios que compõem o Grupo de Trabalho das Grandes Cidades no MEC. Destaque merecido também deve ser dado à coleta de informações por meio de busca detalhada nos sítios eletrônicos alimentados pelas Secretarias de Educação e pelas instituições universitárias, o que permitiu apresentar os programas e ações desenvolvidas por esses órgãos. Os sítios do MEC e das suas respectivas secretarias como as da Educação Básica - SEB - e de Educação Continuada, a de Alfabetização e Diversidade e Inclusão - Secadi -, bem como o sítio da Coordenação de Aperfeiçoamento de Pessoal de Nível Superior Capes -, incluindo buscas no banco de dissertações e teses, constituíram recursos valiosos para o acesso às informações. É necessário fazer aqui um alerta sobre a importância da atualização dos dados desses sítios para as pesquisas.

Para amparar o debate sobre as políticas educacionais e as questões relacionadas à formação e ao trabalho docente, as autoras apresentam, já nos primeiros capítulos, as suas interfaces com o contexto social contemporâneo de modo a inserir as temáticas na dinâmica dos movimentos da sociedade. A compreensão de que as políticas docentes estão profundamente imbricadas com a política educacional mais ampla e especialmente a que envolve o financiamento da educação e os modos de gestão do currículo, exigiu uma reflexão apoiada em pesquisadores nacionais e internacionais. As várias modalidades de avaliação de sistema em larga escala introduzidas pelo MEC a partir da reforma educativa dos anos de 1990 e a criação de sistemas similares por alguns estados da federação são apresentadas de forma cronológica e problematizadas e indicam seu papel regulador das políticas de currículo e, em decorrência disso, da prática docente.

A análise da política de financiamento e da avaliação de sistema como fatores que têm contribuído diretamente para o processo de centralização das políticas de currículo permite situar o leitor em relação ao leque de alternativas ensaiadas pelas políticas públicas no sentido de reverter as condições de exercício do magistério e alçar a educação a um novo patamar. É nessa direção que são apontadas as ações federais que têm contribuído para a consolidação de uma política nacional de formação docente orientada pela perspectiva da instituição de um sistema nacional de educação. Esse conjunto de ações do MEC compõe o Plano Nacional de Formação de Professores da Educação Básica - Parfor - que busca articular-se com as Secretarias Estaduais e Municipais de Educação e as instituições formadoras para ministrar cursos de licenciatura aos que não possuem a formação em 
curso superior e já atuam como docentes. Os vários programas destinados à formação continuada de professores, entre os quais o Pró-Letramento, o Gestar II e a Especialização em Educação Infantil que compõem a Rede Nacional de Formação Continuada, agora redimensionada pelo Parfor, foram também examinados de forma a compor uma visão da política nacional de formação de professores em serviço.

As autoras exploram com propriedade, e sem se esquivar das críticas, um dos principais instrumentos de execução das políticas do Ministério de Educação criado em 2006, a Universidade Aberta do Brasil - UAB. Ao apontar os objetivos da UAB de reduzir as desigualdades na oferta da educação superior, ainda majoritariamente sob a responsabilidade da iniciativa privada, e desenvolver amplo sistema nacional de educação superior a distância, as pesquisadoras sinalizam de forma positiva o esforço de expansão e abrangência dos cursos de formação de professores pelo sistema público. Apontam, contudo, as dificuldades a serem superadas, dentre elas o fato de a expansão nem sempre ser acompanhada de um diagnóstico seguro e de discussão sobre os elementos do currículo, abordagem pedagógica e as formas de acompanhamento e avaliação que atendam às especificidades locais e dos alunos em formação. Quando destacam o papel indutor dos programas do MEC com sua forte presença em todos os estados e na maioria dos municípios e as formas de colaboração entre eles, alertam sobre a falta de clareza quanto à articulação com as políticas formuladas pelos mesmos estados e municípios no exercício de sua autonomia. Também chamam a atenção sobre os frágeis mecanismos de acompanhamento e controle de execução dos programas, que passam ao largo dos canais regulares de gestão das administrações estaduais e municipais. Registram ainda a necessidade de pesquisas de avaliação dos processos de implementação e do impacto dos programas de formação oferecidos pelo MEC.

As ações políticas de formação inicial de professores enfeixam o conjunto de programas postos em prática pelo governo federal nos últimos anos, como o Programa de Reestruturação e Expansão das Universidades Federais - Reuni -, a UAB, o Pró-Licenciatura, Programa Universidade para Todos - ProUni -, o Parfor, o Programa Institucional de Bolsas de Iniciação à Docência - Pibid -, bem como pelos governos estaduais como o Programa Especial de Formação de Professores para a Educação Básica da Zona Rural Profir -, no Acre, o Programa Bolsa Estágio Formação Docente, no Espírito Santo, e o Bolsa Formação: Escola Pública e Universidade, do Estado de São Paulo. Ficou evidenciada, pelos dados e pelas análises, uma crise na formação inicial de professores para a educação básica, tal como normatizada e oferecida pelas IES, especialmente nos aspectos relativos à dinâmica curricular, aí incluídos os estágios, tanto nos cursos presenciais como nos a distância, e à precária formação dos docentes que neles atuam. As autoras resgatam, no entanto, as importantes iniciativas de aproximação universidade-escola estimuladas pelo Pibid do MEC e os dois programas estaduais já menciona- 
dos - o do Estado do Espírito Santo e o do Estado de São Paulo. Destacam também a preocupação do MEC em relação à formação dos docentes para os anos iniciais do ensino fundamental e às ações no sentido de aprimorar os instrumentos avaliativos desses cursos. A intencionalidade posta em documentos e regulamentações é considerada alentadora pelas autoras, mas deixa um questionamento sobre a força política dos gestores na implementação das reais e fortes mudanças institucionais e curriculares em relação à formação de professores.

A questão salarial e de carreira dos professores da educação básica é tratada mediante exames de planos de carreira obtidos junto às Secretarias Estaduais e Municipais e contempla dados das diferentes regiões do país. A análise indica que os ajustes em relação ao que a legislação tem determinado e outras orientações propostas em nível federal ainda não foram incorporados pelas legislações de vários estados e municípios. Considera, entretanto, que houve avanços significativos nos últimos cinco anos e constata uma movimentação em torno dos planos de carreira nessas duas instâncias. Também indica que, em relação à cobertura das despesas necessárias à valorização da docência, é preciso um processo de articulação mais eficaz entre a União, estados e municípios no sentido de garantir melhorias no financiamento da educação e de assegurar acordos políticos de largo espectro.

A análise das ações políticas dos estados baseou-se sobretudo nos dados coletados nos documentos oficiais e nos estudos de campo e foi direcionada a secretarias que possuíam ações voltadas ao fortalecimento da docência. As autoras destacaram os programas inovadores desenvolvidos por seis Secretarias Estaduais de Educação no que se refere às ações de formação continuada, identificando as características originais e traços recorrentes que informaram as ações de cada um, indicando os percursos diversos e reconhecendo os avanços, consideradas as referências analíticas trazidas pela literatura sobre o tema. Uma indicação desse avanço é o esforço de algumas secretarias para mudar o modelo de formação continuada e centrá-lo nas escolas e não em cursos, seminários e palestras.

Os dados do estudo de campo indicaram que as Secretarias Estaduais e Municipais analisadas são dotadas de recursos materiais e de infraestrutura para a realização do trabalho pedagógico, providos em grande parte pela disponibilidade dos recursos provenientes do Fundo de Manutenção e Desenvolvimento da Educação Básica e de Valorização dos Profissionais da Educação - Fundeb. Também apontaram que há um processo de melhor qualificação dos quadros gestores dessas secretarias e que os apoios didático-pedagógicos oferecidos aos professores está centrado, em geral, no desenvolvimento de uma proposta curricular. Os processos de formação continuada como forma de apoio ao trabalho dos professores mostraram avanços ao privilegiarem ações de formação focalizadas no desenvolvimento dessa proposta curricular, embora em sua forma mais tradicional, como oficinas, palestras e cursos presenciais e a distância. Duas das secretarias 
analisadas constituíram exceção a esse formato. As iniciativas das Secretarias de Educação em relação à política de valorização do magistério, seja pela socialização de práticas exitosas ou pelo incentivo à qualificação por meio de bolsas ou afastamento remunerado e a atribuição de prêmios ou dinheiro aos professores ou à escola com bom desempenho, foram identificadas e analisadas com ponderações das autoras, especialmente em relação à concessão de bônus em dinheiro aos professores. Também foram destacadas iniciativas inovadoras em relação à política de apoio aos professores iniciantes.

Nas conclusões, as autoras chamam a atenção sobre a predominância de ações pautadas pelos resultados das avaliações padronizadas dos alunos da educação básica, o que representa, segundo elas, um indicativo de maior mobilização das redes de ensino e de suas políticas, agora mais focalizadas nos alunos e no direito de aprender. Isso sinaliza que as formas de condução, controle e avaliação da atuação docente também passam por alterações.

Um aspecto importante reforçado nas conclusões se refere à aderência das propostas entre os entes federados. Corre-se o risco, caso a aderência não se concretize, de comprometer a sustentação das conquistas, bem como das possibilidades de desenvolvimento profissional dos docentes. Também a aderência dos professores aos modelos de intervenção propostos no interior das redes de ensino definirá o sucesso das políticas.

A publicação representa um esforço ousado das pesquisadoras ao apresentar informações que permitem compreender as atuais políticas docentes do país, seus avanços e aspectos que demandam maior atenção dos gestores públicos. O livro vem preencher uma lacuna na discussão sobre as atuais políticas de formação docente e seus processos de implementação. A obra constitui uma referência valiosa para pesquisadores, gestores, professores e futuros docentes e para aqueles que se dedicam ao estudo das políticas públicas.

\section{LAURIZETE FERRAGUT PASSOS}

Professora do Programa de Estudos Pós-Graduados em Educação Matemática da Pontifícia Universidade Católica de São Paulo laurizetefer@pucsp.br 